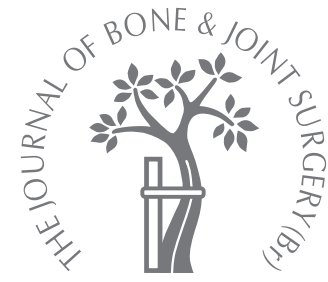

A. Clarke, M. J. Hutton, D. Chan

From Peninsula Spine Unit, Princess

Elizabeth

Orthopaedic Centre, Royal Devon and Exeter Hospital, Exeter, England
A. Clarke, FRCS(Orth) Consultant Orthopaedic Spinal Surgeon

M. J. Hutton, BSc, FRCS(Trauma \& Orth)

Consultant Orthopaedic Spinal Surgeon

D. Chan, FRCSEd,

FRCS(Orth), Consultant

Orthopaedic Spinal Surgeon

Peninsula Spine Unit, Princess

Elizabeth Orthopaedic Centre

Royal Devon and Exeter

Hospital, Barrack Road, Exeter EX2 5DW, UK.

Correspondence should be sent to Mr A. Clarke; e-mail: kluver_bucy@hotmail.com

(C)2010 British Editorial Society of Bone and Joint Surgery doi:10.1302/0301-620X.92B7. $24060 \$ 2.00$

$J$ Bone Joint Surg $[\mathrm{Br}]$ 2010;92-B:1023-4.

Received 27 November 2009, Accepted 9 February 2010

- CASE REPORT

\title{
Respiratory failure due to a displaced fracture of the odontoid
}

Fractures of the odontoid peg are relatively common in elderly people. Often they are minimally displaced and can be treated with a collar. However, a fracture which is displaced significantly may be difficult to manage. We describe the case of an 80 -year-old man with a fracture of the odontoid peg which was completely displaced and caused respiratory distress. After initial closed reduction and application of a halo jacket, open and internal fixation was undertaken and relieved his symptoms. It is a safe and effective way to manage this injury.

Odontoid fractures are relatively common in the elderly ${ }^{1}$ and are usually the result of lowenergy trauma. They are often minimally displaced, and can be managed in a semi-rigid cervical collar. If they are very displaced, reduction and some form of fixation is required. Neurological involvement is uncommon after these injuries, yet they are potentially fatal. ${ }^{2}$

We describe the case of a previously healthy 80-year-old farmer who sustained a completely displaced fracture of the odontoid process which caused respiratory compromise until the fracture was reduced.

\section{Case report}

An 80-year-old farmer with no significant medical history sustained a head injury and a fracture of the odontoid peg when struck by a bullock at a country fair. He was admitted to our hospital and immobilised with full spinal precautions. He had a Glasgow coma score of 15 on admission and was moving all four limbs normally.

A CT scan of his head and neck (Fig. 1) revealed a posteriorly displaced type 2 fracture of the odontoid peg. ${ }^{3} \mathrm{He}$ was initially treated in a semi-rigid cervical collar, without reduction of the fracture. His neurological condition, however, deteriorated with his Glasgow coma score falling to 12. A further CT scan showed no changes from the previous position.

Review by the medical and critical care teams revealed a respiratory acidosis which the orthopaedic team thought could be explained by the displacement of his odontoid peg. He therefore underwent reduction of the fracture and the application of a halo jacket.

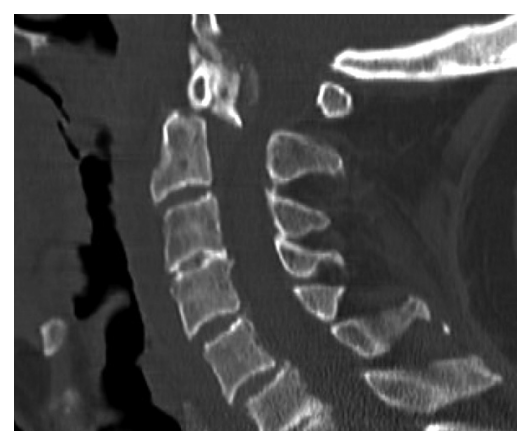

Fig. 1

Sagittal CT scan of the upper cervical spine showing a displaced fracture of the odontoid peg.

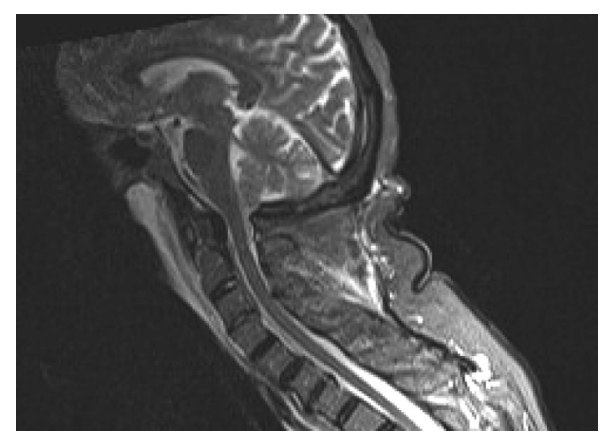

Fig. 2

Sagittal MR scan of the upper cervical spin after reduction. 


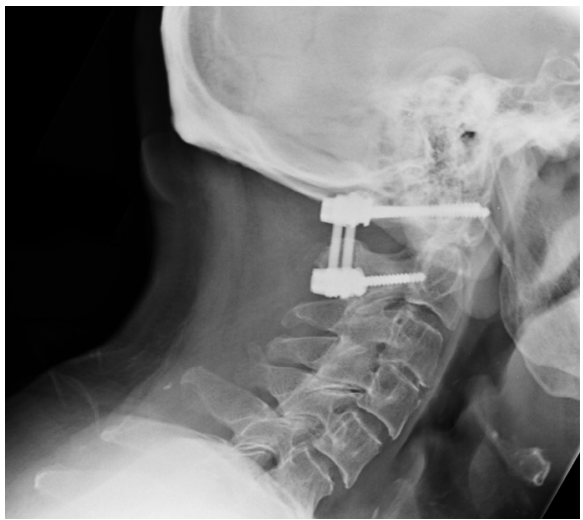

Fig. 3

Lateral radiograph at one year showing the fixation.

He was intubated and the respiratory acidosis was corrected.

He next underwent an MR scan (Fig. 2), which showed the odontoid to be reduced in the halo body jacket. He was deemed fit for surgery 48 hours later and underwent a posterior fixation of C1-2 (Fig. 3). He improved dramatically and, at the last follow-up had returned to farming.

\section{Discussion}

The control of respiration resides within the medulla. In addition, the upper cervical spinal cord contains respiratory pathways ${ }^{4}$ that run in the anterolateral quarter of the cord and are thought to extend to at least the fourth cervical vertebra. ${ }^{5}$
A posteriorly displaced fracture of the odontoid peg that compresses the spinal cord can compromise respiration and cause a respiratory acidosis. Prompt realignment of the spine is required to correct this. Harrop et al ${ }^{1}$ noted more patients with respiratory difficulties if the fracture of the odontoid was displaced posteriorly. They ascribed the problem to retropharyngeal swelling after reduction of the fracture but we believe that it may be due to pressure in the respiratory pathways in the upper cervical cord.

We advise early reduction of this fracture. How the reduction is maintained is a matter for debate. However, we have found that posterior C1-2 fixation gives reliable and reproducible results. ${ }^{6}$ It allows early rehabilitation of the patient without the problems associated with external orthoses and it is a surgical technique which is well tolerated by the elderly. ${ }^{7}$

No benefits in any form have been received or will be received from a commercial party related directly or indirectly to the subject of this article.

\section{References}

1. Harrop JS, Vaccaro A, Przybylski GJ. Acute respiratory compromise associated with flexed cervical traction after C2 fractures. Spine 2001;26:E50-4.

2. Lewallen RP, Morrey BF, Cabanela ME. Respiratory arrest following posteriorly displaced odontoid fractures: case reports and review of the literature. Clin Orthop 1984; 188:187-90

3. Anderson LD, D'Alonzo RT. Fractures of the odontoid process of the axis. J Bone Joint Surg [Am] 1974;56-A:1663-74.

4. Fielding JW, Tuul A, Hawkins RJ. "Ondine's curse": a complication of upper cervical-spine surgery. J Bone Joint Surg [Am] 1975;57-A:1000-1.

5. Belmusto L, Brown E, Owens G. Clinical observations on respiratory and vasomotor disturbances as related to cervical cordotomies. J Neurosurg 1963;20:225-32.

6. Harms J, Melcher RP. Posterior C1-C2 fusion with polyaxial screw and rod fixation. Spine 2001;26:2467-71.

7. Stulik J, Vyskocil T, Sebesta P, Kryl J. Atlantoaxial fixation using the polyaxial screw-rod system. Eur Spine J 2007;16:479-84. 